\title{
miR-767-5p inhibits glioma proliferation and metastasis by targeting SUZ12
}

\author{
JIALE ZHANG ${ }^{1 *}$, SHUO XU ${ }^{2 *}$, JIA XU $^{1 *}$, YANGYANG LI $^{1}$, JIE ZHANG $^{1}$, \\ JIAN ZHANG $^{1}$ and XIAOMING LU ${ }^{1}$ \\ ${ }^{1}$ Department of Neurosurgery, The First Affiliated Hospital of Nanjing Medical University, \\ Nanjing, Jiangsu 210029; ${ }^{2}$ Department of Intensive Care Unit, \\ Zhenjiang First People's Hospital, Zhenjiang, Jiangsu 212002, P.R. China
}

Received April 9, 2018; Accepted April 9, 2019

DOI: $10.3892 / o r .2019 .7156$

\begin{abstract}
A growing body of evidence implicates aberrant expression of microRNAs (miRNAs) and dysregulation of mRNA translation in the development and growth of cancer cells. However, little is known about the mechanisms of action of miRNAs in glioma, the most common form of adult-onset malignant brain tumor. In the present study, the expression and function of miR-767-5p were examined in human glioblastoma multiforme (GBM) tissue specimens and cell lines. miR-767-5p expression levels were analyzed by quantitative reverse-transcription PCR; cell proliferation was assessed by CCK-8, colony formation and 5-ethynyl-2'-deoxyuridine (EDU) assays; the cell cycle phase and apoptosis were detected by flow cytometry; and cell invasiveness was analyzed using wound healing and Transwell invasion assays. It was revealed found that miR-767-5p was significantly upregulated in GBM tissues $(n=18)$ compared with normal brain tissues $(n=8)$ and in 6 GBM cell lines compared with normal human astrocytes. Ectopic expression of miR-767-5p suppressed proliferation, colony formation, and migration, and promoted cell cycle arrest and apoptosis in GBM cell lines in vitro, and inhibited GBM tumor growth in a mouse xenograft model. Bioinformatics analysis identified the PRC2 component suppressor of zeste-12 (SUZ12) as a putative target of miR-767-5p. Co-transfection of miR-767-5p inhibited the activity of a luciferase reporter construct driven by the wild-type $3^{\prime}$ untranslated region of SUZ12 mRNA, but this was abolished by mutation of the putative miR-767-5p-binding sites. Consistent with the possibility that miR-767-5p acts by regulating SUZ12 expression, it was
\end{abstract}

Correspondence to: Professor Xiaoming Lu, Department of Neurosurgery, The First Affiliated Hospital of Nanjing Medical University, 300 Guangzhou Road, Nanjing, Jiangsu 210029, P.R. China

E-mail: luxm923@126.com

*Contributed equally

Key words: miR-767-5p, GBM, SUZ12, proliferation, invasion revealed that the inhibitory effects of miR-767-5p on GBM cell phenotypes were reversed by overexpression of SUZ12. Our results indicated that forced upregulation of miR-767-5p may represent a novel therapeutic strategy for glioma patients by targeting SUZ12.

\section{Introduction}

Glioma, the most common malignant primary brain tumor in adults, is highly invasive and has a poor prognosis (1). Of the 4 classes of glioma classified by the World Health Organization (WHO), the highest grade (grade IV) is glioblastoma multiforme (GBM) (2). Despite recent advances in our understanding of the biology of GBM and extensive efforts to develop new therapeutic options (3), the prognosis is dire, and the median survival time of 15 months has not changed over the last 20 years (4). Therefore, there is an urgent need to identify novel diagnostic biomarkers and potential therapeutic targets for this devastating disease.

MicroRNAs (miRNAs) are a class of small ( 18-25 nucleotides) non-coding single-stranded RNAs (5), and are increasingly recognized to play key regulatory roles in numerous physiological processes in plants and animals (6). miRNAs are crucial regulators of gene expression, and function by binding to partially complementary sequences in the 3' untranslated region (3'UTR) of mRNAs, thereby preventing their translation and/or degradation (7-10). Substantial evidence implicates dysregulated expression and/or function of miRNAs in promoting or inhibiting the development and progression of cancer, suggesting they can act as tumor suppressors or oncogenes (11-13). Among the cancer-related processes influenced by aberrant miRNA expression are cell apoptosis, proliferation, invasion, and resistance to chemotherapeutic agents (14-17). One of the first miRNAs to be described was miR-21 originally discovered in Caenorhabditis elegans, which is aberrantly expressed in many human cancers and contributes to the malignant phenotype by targeting critical tumor suppressor genes (18). Although there is increasing recognition of the potential diagnostic and therapeutic utility of miRNAs in cancer $(19,20)$, relatively little is known about the role of miRNAs in glioma development and progression. 
Suppressor of zeste-12 (SUZ12) is a core protein of the Polycomb repressive complex 2 (PRC2), which also includes EED, EZH2, and RBBP4 and RBBP7 proteins. PRC2 catalyzes the trimethylation of histone $\mathrm{H} 3$ lysine 27 (H3K27me3), which is associated with repression of gene transcription (21). In human embryonic fibroblasts, $>1,000$ genes are silenced by PRC2 activity (22). Moreover, aberrant expression of PRC2 has been revealed to contribute to various human diseases and disorders, particularly cancer. In fact, many recent studies have demonstrated that PRC 2 is overexpressed in a variety of cancers, where it plays a key role in preventing the expression of tumor suppressor genes during cell transformation (23-25). SUZ12 has been revealed to be aberrantly expressed in many types of cancer, including bladder cancer (26), gastric carcinoma (27) and mantle cell lymphoma (28). However, the precise expression pattern and function of SUZ12 in glioma remains unclear.

In the present study, it was revealed that the expression of miR-767-5p was significantly downregulated in GBM tissue samples and cell lines compared with their normal counterparts. It was determined that ectopic expression of miR-767-5p inhibited many cancer-related phenotypes of GBM cells. In addition, SUZ12 was identified as a direct target of miR-767-5p, and SUZ12 expression in GBM tissue was revealed to be negatively correlated with miR-767-5p levels. Finally, it was determined that miR-767-5p overexpression significantly suppressed tumor growth in a mouse xenograft model of GBM. Collectively, our findings indicate a crucial potential role for miR-767-5p in GBM.

\section{Materials and methods}

Human tissue samples. Human GBM samples $(\mathrm{n}=18)$ and normal brain tissues (NBTs; $n=8$ ) were collected from patients at the Department of Neurosurgery at the First Affiliated Hospital of Nanjing Medical University, China. Fresh specimens were immediately frozen in liquid nitrogen and stored at $-80^{\circ} \mathrm{C}$ until analyzed. Histopathological grading was based on the WHO criteria. None of the GBM patients had undergone chemotherapy or radiotherapy prior to surgery. The present study was approved by the Research Ethics Committee of Nanjing Medical University, and written informed consent was obtained from all patients.

Cell culture. The human GBM cell lines T98, A172, U87 (glioblastoma of unknown origin; STR profiling was performed), LN229, U251 and U118 (derived from the U138MG astrocytoma cell line; STR profiling was performed) were obtained from the Chinese Academy of Sciences Cell Bank (Shanghai, China). All cells were cultured in Dulbecco's modified Eagle's medium (DMEM) with high glucose and sodium pyruvate, supplemented with $10 \%$ fetal bovine serum (FBS) and antibiotics (100 U/ml penicillin and $100 \mathrm{ng} / \mathrm{ml}$ streptomycin). Cells were maintained in a $5 \% \mathrm{CO}_{2}$ atmosphere at $37^{\circ} \mathrm{C}$. Normal human astrocytes (NHAs) were purchased from Lonza (Walkersville, MD, USA) and cultured according to the supplier's instructions. Human 293T cell lines were purchased from the American Type Culture Collection (ATCC; Rockville, MD, USA).

Lentiviral packaging and generation of stable cell lines. A lentiviral packaging kit was purchased from Shanghai
GeneChem Co., Ltd. (Shanghai, China). The hsa-miR-767-5p mimic and hsa-miR-negative control (miR-NC) sequences were chemically synthesized by Guangzhou RiboBio Co., Ltd., Guangzhou, China). Next, $293 \mathrm{~T}$ cells were infected with the vectors, and lentiviruses were collected from the supernatant according to the manufacturer's instructions. U87 and U251 cells were infected with lentiviruses for $24 \mathrm{~h}$ and selected with puromycin $(1 \mu \mathrm{g} / \mathrm{ml})$ to establish stable cell lines. For SUZ12 overexpression, human SUZ12 cDNA was cloned into pcDNA3.1 to generate pCDNA3.1-SUZ12. Cells were transfected with miR-767-5p, miR-NC, empty pCDNA3.1, or pCNDA-SUZ12 using Lipofectamine 2000 (Invitrogen; Thermo Fisher Scientific, Inc., Waltham, MA, USA) according to the manufacturer's protocol. Cells were used for experiments at $48 \mathrm{~h}$ after transfection as indicated.

$R N A$ extraction and quantitative reverse-transcription PCR $(R T-q P C R)$. Total RNA was extracted from cells or tissues using TRIzol (Invitrogen; Thermo Fisher Scientific, Inc.), following the manufacturer's protocol. miR-767-5p levels were assessed by RT-qPCR was performed using an ABI StepOne Plus System (Applied Biosystems; Thermo Fisher Scientific, Inc.) with a Bulge-Loop ${ }^{\text {TM }}$ miRNA RT-qPCR Primer Kit (Guangzhou RiboBio Co., Ltd.) and primers purchased from Guangzhou RiboBio Co., Ltd. miRNA levels were normalized to U6 mRNA and quantified using the $2^{\Delta \Delta \mathrm{Cq}}$ method (29).

Protein extraction and immunoblotting. Cells were harvested from 6-well plates and lysed in RIPA lysis buffer (Shanghai Beyotime Biotechnology China, Shanghai, China). Protein concentrations were determined using the bicinchoninic acid assay (KenGen, Jiangsu, China). Western blotting was performed as previously described (30). SUZ12 (cat. no. ab126577) were purchased from obtained from Abcam (Cambridge, UK). p-ERK1/2 (cat. no. 4370), total-ERK1/2 (cat. no. 4695), p-AKT (cat. no. 4060), total-AKT (cat. no. 4691), were purchased from Cell Signaling Technology (Beverly, MA, USA). $\beta$-actin (AA128) were obtained from Beyotime Institute of Biotechnology. Secondary antibody mouse (cat. no. A1902) and rabbit (cat. no. A0208) came from Beyotime Institute of Biotechnology. In brief, proteins were separated by $10 \%$ SDS-PAGE and transferred to nitrocellulose membranes (Thermo Fisher Scientific, Inc.). After blocking in $5 \%$ non-fat milk for $2 \mathrm{~h}$, the membranes were incubated with primary antibodies against SUZ12 (dilution 1:100), p-ERK1/2 (dilution 1:2,000), total-ERK1/2 (dilution 1:1,000), p-AKT (dilution 1:2,000), total-AKT (dilution 1:1,000), and $\beta$-actin $(1: 1,000)$ overnight under $4^{\circ} \mathrm{C}$. They were then incubated with secondary antibodies for $2 \mathrm{~h}$ at room temperature. Electrochemiluminescence detection system (Thermo Fisher Scientific) was used for signal detection. Signals were examined by densitometric scans using ImageJ software (version 1.51; available at http://rsb.info.nih.gov/ij/) for Pearson's correlation analysis.

miRNA target prediction. Potential miR-767-5p targets were identified using the online predictive program miRBase Targets (http://www.diana.pcbi.upenn.edu/cgi-bin/miRGen/v3/Targets. cgi \#Results), TargetScan Release 7.0 (http://www.targetscan. org/). 
Dual-luciferase reporter assay. The 3'UTR of SUZ12 mRNA containing the wild-type sequence (WT) or containing mutations in the putative miR-767-5p binding site (Mut) were amplified and cloned into the pmiRNA-Report luciferase expression reporter vector (Shanghai GeneChem Co., Ltd.). Luciferase reporter assays were performed as previously described (31). In brief, U87 and U251 cells were seeded into 24-well plates for $24 \mathrm{~h}$ and then co-transfected with SUZ12-WT or SUZ12-Mut luciferase vectors along with miR-767-5p or miR-NC using Lipofectamine 2000 (Invitrogen; Thermo Fisher Scientific, Inc.). Luciferase activities were quantified at $24 \mathrm{~h}$ after transfection using the Promega Dual-Luciferase Reporter Assay System (Promega Corp., Madison, WI, USA).

Wound healing assay. Cell migration was examined using wound healing assays conducted as previously described (32). Briefly, U87 and U251 glioma cells were co-transfected with a SUZ12-pCDNA3.1 overexpression vector and either miR-767-5p or miR-NC. After plating, the cell layer was scratched and the cells were incubated for a further $24 \mathrm{~h}$. Cells were examined under a Leica light microscope (Leica Microsystems $\mathrm{GmbH}$, Wetzlar, Germany) and images of the wound area were captured at 0 and $24 \mathrm{~h}$ after injury.

Invasion assay. Cell invasion was assessed using 24-well BD Matrigel invasion chambers (BD Biosciences, Franklin Lakes, NJ, USA) according to the manufacturer's instructions. Briefly, $3 \times 10^{4}$ cells in serum-free DMEM were added to the upper chamber, and DMEM supplemented with 15\% FBS was added to the lower chamber as a chemoattractant. After $24 \mathrm{~h}$, non-invading cells were removed from the top well by scraping, and invaded cells in the lower chamber were fixed with $4 \%$ paraformaldehyde for $15 \mathrm{~min}$ and then stained with $0.1 \%$ crystal violet for $2 \mathrm{~h}$. The wells were photographed and the number of cells in 3 independent x10 magnification fields was counted.

Cell proliferation and colony formation assays. Cells in logarithmic growth phase were seeded at $5 \times 10^{3}$ cells/well in 96-well plates and cultured for the indicated time-points. Cell proliferation was quantified using the Cell Counting Kit-8 (CCK-8; Dojindo Laboratories, Kumamoto, Japan) according to the manufacturer's instructions. For colony-forming assays, cells were seeded at $2 \times 10^{2}$ cells/well in 6-well plates and cultured for $\sim 10$ days. Cells were then fixed with $100 \%$ methanol and stained with $0.1 \%$ crystal violet for $20 \mathrm{~min}$. The number of colonies with a diameter $>0.5 \mathrm{~mm}$ was counted.

Cell cycle analysis and apoptosis assay. For cell cycle analysis, cells were harvested, centrifuged at $360 \mathrm{x}$ g for $5 \mathrm{~min}$, washed with phosphate-buffered saline (PBS), and fixed in $75 \%$ ethanol at $-20^{\circ} \mathrm{C}$ overnight. Fixed cells were washed twice with PBS, stained as described for the Cell Cycle Staining Kit (Hangzhou MultiSciences Biotech, Co., Ltd., (Hangzhou, China), incubated for $25 \mathrm{~min}$ in the dark, and analyzed on a flow cytometer (Beckman Coulter, Inc., Brea, CA, USA). Apoptosis was measured using an Apoptosis Detection Kit (BD Biosciences) according to the manufacturer's protocol.
Cells were analyzed on a Gallios flow cytometer (Beckman Coulter, Inc.).

Xenograft experiments in vivo. Male BALB/c nude mice $(\mathrm{n}=12)$ at 4 weeks of age (weighing $20 \mathrm{~g}$ ) were obtained from the Shanghai Laboratory Animal Center (Shanghai, China). All mice were housed and maintained under specific pathogen-free conditions in laminar flow cabinets. U87 cells transfected with lentiviruses encoding miR-767-5p or miR-NC $\left(5 \times 10^{5}\right)$ were injected subcutaneously into the posterior flanks of the mice ( $n=6 /$ group) and tumor growth was monitored for 30 days. Tumor sizes were measured every 3 days using calipers, and the volume $\left(\mathrm{mm}^{3}\right)$ was calculated as (lengthxwidth $\left.{ }^{2}\right) / 2$. The mice were sacrificed 30 days after injection, and the tumors were excised, weighed and photographed. Tumor samples were fixed with $4 \%$ paraformaldehyde, embedded in paraffin, and processed for immunohistochemical (IHC) staining as described below. All animal experiments were approved by the Animal Management Rule of the Chinese Ministry of Health (Document 55, 2001) and were conducted in accordance with the approved guidelines and experimental protocols of Nanjing Medical University.

Immunohistochemistry. IHC analysis of fresh brain tissue or excised tumor xenografts was performed as previously described (33) using anti-SUZ12 (dilution 1:500) and anti-Ki-67 (dilution 1:150; cat. no. ab156956) purchased form Abcam (Cambridge, MA, USA).

Fluorescence in situ hybridization (FISH). miR-767-5p expression in GBM and NBT samples was detected by FISH. A 5'-FAM-labeled miR-767-5p sequence (5'-CATGCT CAGACAACCATGGTGCA-3') was synthesized by GoodBio Technology Co., Ltd. (Wuhan, China). FISH was performed according to a protocol provided by BioSense (Guangzhou, China). In brief, frozen tissues were fixed in $4 \%$ formaldehyde for $20 \mathrm{~min}$, washed twice for $3 \mathrm{~min}$ each with PBS, digested with proteinase $\mathrm{K}$ for $5 \mathrm{~min}$, and washed twice again with PBS. After eliminating auto-fluorescence and blocking endogenous biotin, the sections were hybridized with the probes overnight at $42^{\circ} \mathrm{C}$ in a humid chamber. The sections were then washed with $2 \mathrm{X}$ saline-sodium citrate (SSC) for $10 \mathrm{~min}, 1 \mathrm{X}$ SSC for $10 \mathrm{~min}$, and $0.5 \mathrm{X}$ SSC for $10 \mathrm{~min}$ at room temperature. Finally, the sections were stained with 4',6-diamidino-2-phenylindole (DAPI) for 15 min and examined with a ZEISS LSM 700 Meta confocal microscope (Zeiss AG, Oberkochen, Germany).

Statistical analysis. Data are presented as the mean \pm standard deviation (SD). Associations between miR-767-5p and SUZ12 levels in glioma tissues were analyzed using Pearson's correlation analysis. For the remaining experiments, and all data were analyzed by the Student's t-test for pairwise comparison or one-way analysis of variance (ANOVA) followed by Bonferroni test for multivariate analysis. Differences were considered statistically significant at $\mathrm{P}<0.05$.

\section{Results}

miR-767-5p expression is decreased in human glioma specimens and cell lines. To determine whether miR-767-5p may 
A

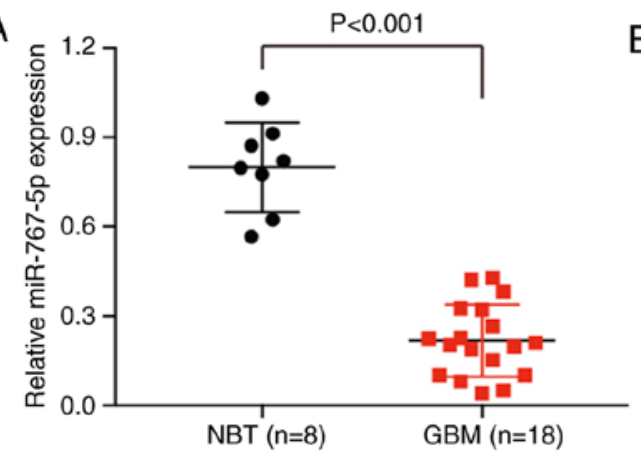

B

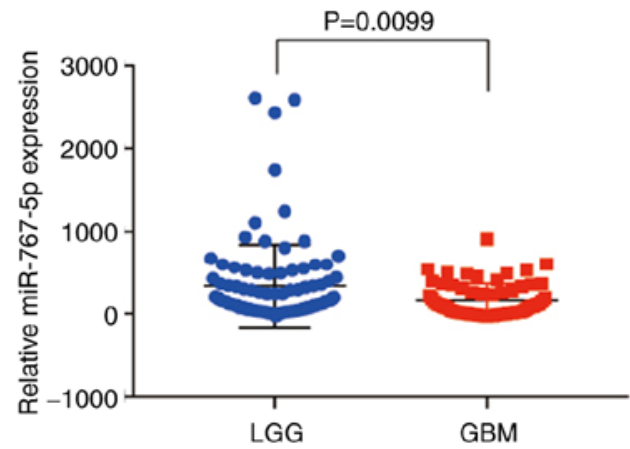

C

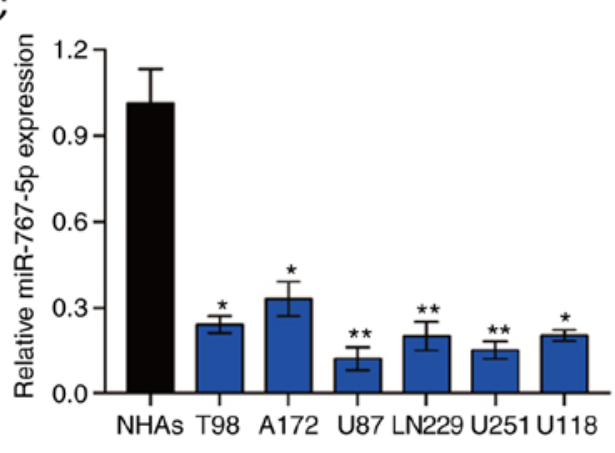

D

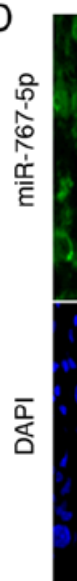

GBM

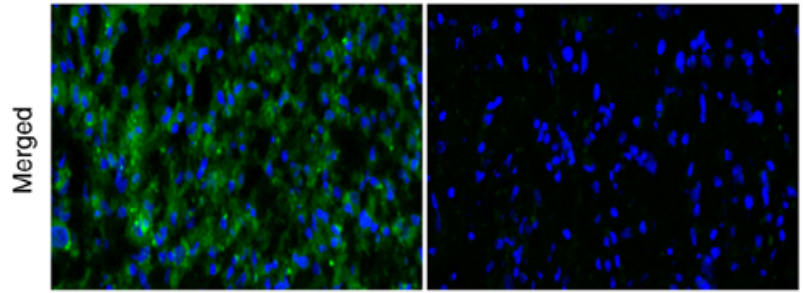

Figure 1. miR-767-5p is downregulated in GBM specimens and cell lines compared with normal brain tissues and NHAs. (A) RT-qPCR analysis of miR-767-5p expression in 8 normal brain specimens and 18 GBM tissue specimens. (B) miR-767-5p expression in GBM tissues ( $\mathrm{n}=94$ ) and (LGG $\mathrm{n}=64)$ based on data from the CGGA database. (C) RT-qPCR analysis of miR-767-5p levels in NHAs and 6 glioma cell lines. (D) Representative images revealing FISH analysis of miR-767-5p expression in GBM and NBT. Nuclei were stained with DAPI. Data are presented as the means \pm SD. ${ }^{*} \mathrm{P}<0.05$, ${ }^{* *} \mathrm{P}<0.01$ compared to NHAs. GBM, glioblastoma multiforme; NHAs, normal human astrocytes; LGG, low-grade glioma; CGGA, Chinese Glioma Genome Atlas; FISH, fluorescence in situ hybridization; NBT, normal brain tissue; SD, standard deviation.

play a role in the development and/or progression of glioma, we first analyzed its expression in 8 NBT samples and 18 histologically confirmed GBM samples by RT-qPCR. The analysis revealed that miR-767-5p levels were significantly lower in GBM tissues compared with NBTs (Fig. 1A). To validate this finding, miR-767-5p expression was evaluated in 158 glioma tissues of different grades, based on data obtained from the Chinese Glioma Genome Atlas (CGGA) database. Similarly, it was revealed that miR-767-5p was significantly lower in GBM tissue compared with low-grade glioma (grade II and III) (Fig. 1B). Next, the expression of miR-767-5p was assessed in a panel of 6 glioma cell lines (T98, A172, U87, LN229, U251 and U118) and normal human astrocytes (NHAs). Consistent with the results of the tissue analyses, miR-767-5p levels were significantly lower in all 6 glioma cell lines compared with NHAs (Fig. 1C). Finally, FISH was performed on sections of GBM and NBTs, which confirmed the marked downregulation of miR-767-5p in GBM compared with normal brain samples
(Fig. 1D). Collectively, these data raise the possibility that the loss of miR-767-5p expression in GBM may be involved in the development and/or progression of glioma.

Overexpression of miR-767-5p suppresses glioma cell proliferation and invasiveness and induces apoptosis. To investigate the potential biological functions of miR-767-5p in vitro, U87 and U251 cells were transfected with lentiviral vectors encoding miR-767-5p or a control miRNA sequence (miR-NC), and then the effects on various cancer-related behaviors were analyzed. A specially constructed lentivirus for miR-767-5p was transfected into U87 and U251 cells to alter the expression level of miR-767-5p. RT-qPCR revealed that miR-767-5p was significantly increased compared to negative control groups (Fig. 2A). As revealed in Fig. 2B and C, the expression of the miR-767-5p mimic significantly reduced a wide range of functions compared with untransfected or miR-NC-transfected cells, including proliferation (Fig. 2B) and colony formation 
A

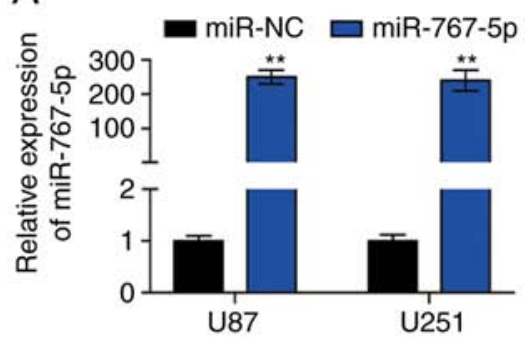

B

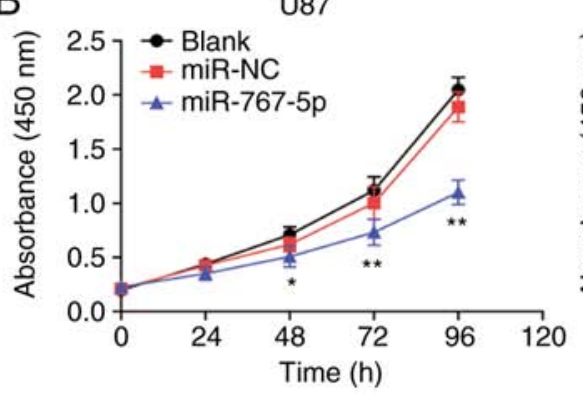

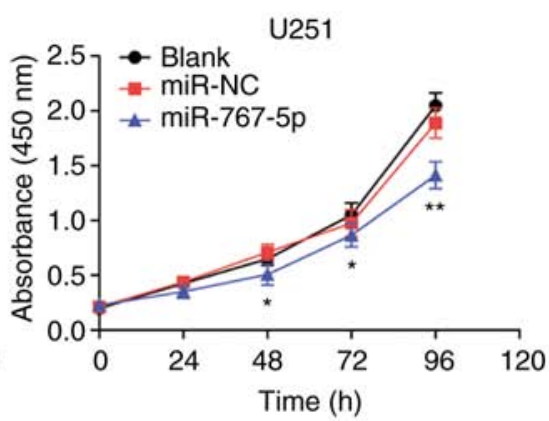

U251
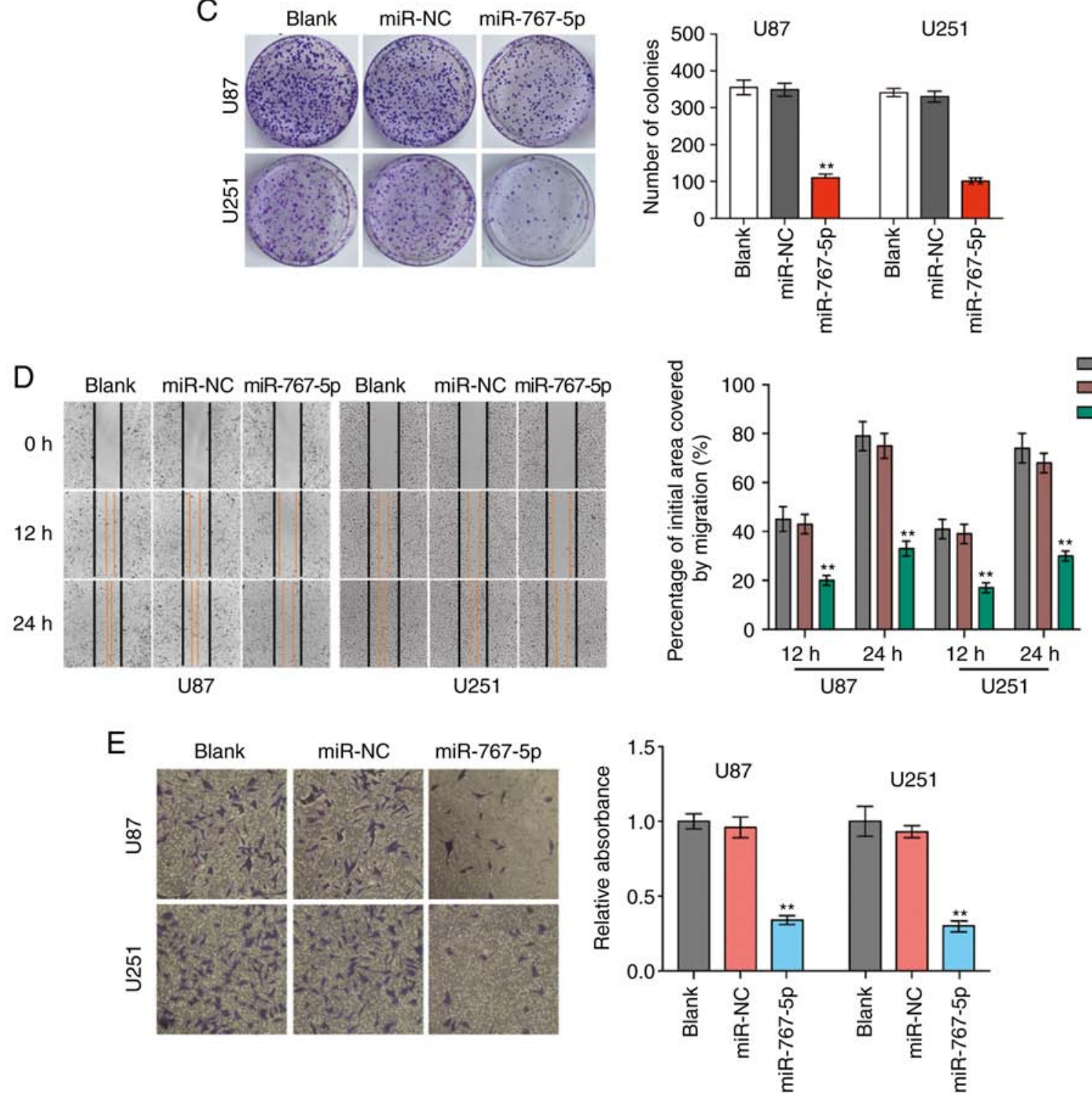

Figure 2. Overexpression of miR-767-5p affects cancer-related behaviors of GBM cells. (A-G) For all assays, U87 and U251 cells were untransfected (blank) or transfected with a miR-767-5p mimic or a negative control sequence (miR-NC). (A) The relative expression of miR-767-5p in U87 and U251 cells was analyzed by RT-qPCR after transfection. (B) CCK-8 proliferation assay. (C) Representative images (left) and quantification (right) of colony formation assays performed after 10 days in culture. (D) Representative images (left) and quantification (right) of wound healing assays performed in U87 and U251 cells. (E) Representative images (left) and quantification (right) of Transwell migration assays.

(Fig. 2C). In addition, wound healing and Transwell invasion assays were performed to evaluate GBM cell migration and invasion, respectively. Cells overexpressing miR-767-5p revealed significantly reduced migratory and invasive behaviors compared with un-transfected or miR-NC-transfected cells (Fig. 2D and E). Finally, the effects of miR-767-5p overexpression on GBM cell cycle progression and apoptosis were evaluated. The proportion of cells in G1 phase and G2/S phases was increased and decreased, respectively, by expression of miR-767-5p compared with miR-NC (Fig. 2F). Consistent with this result, miR-767-5p overexpression resulted in an increase in the number of apoptotic U87 and U251 cells 

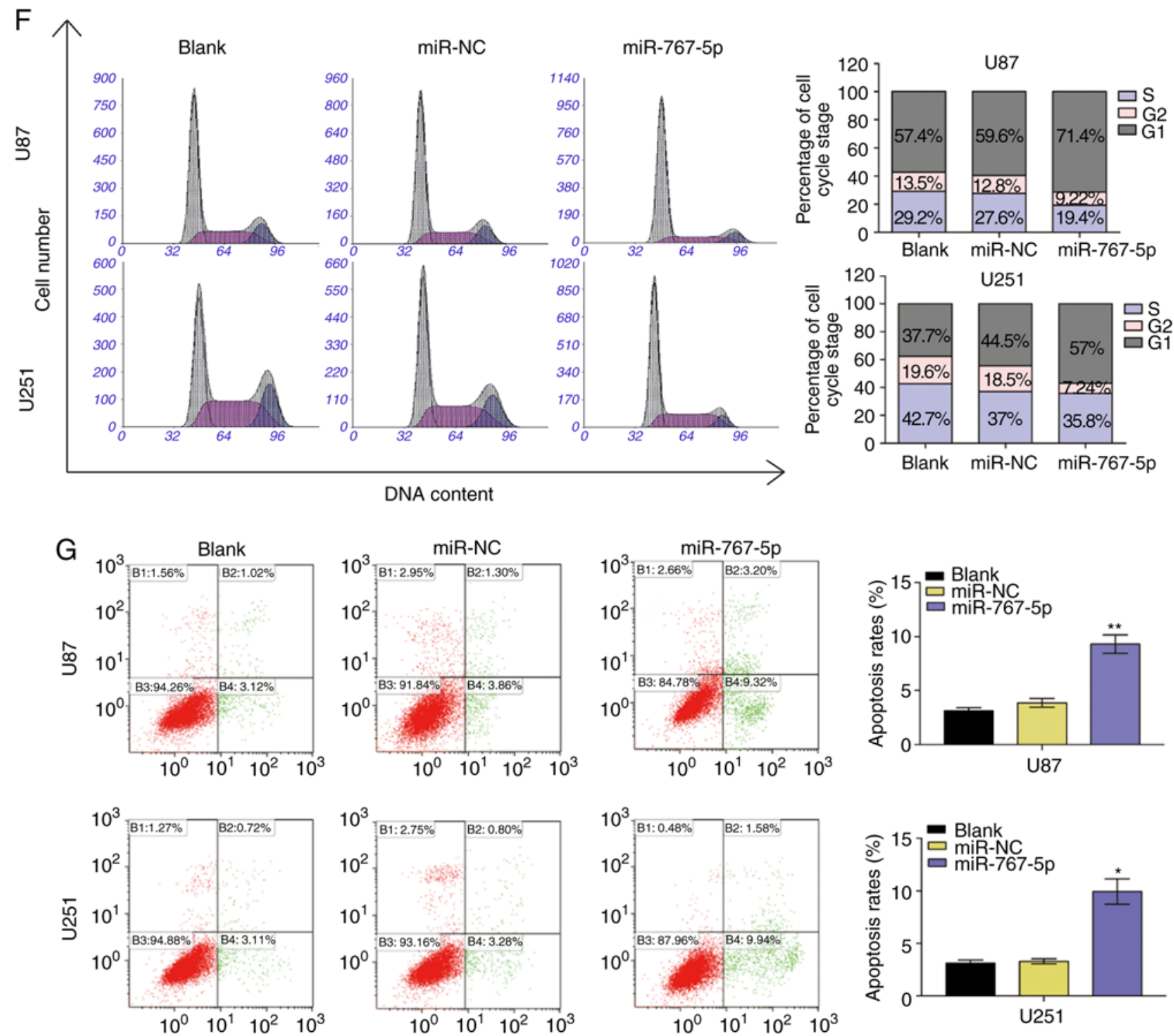

Figure 2. Continued. (F) Flow cytometric analysis of the cell cycle by staining with PI (DNA content). Representative histograms (left) and quantification (right) of cells in G1, G2, and S phases of the cell cycle. (G) Representative dot plots (left) and quantification (right) of an Annexin V-FITC/PI apoptosis assay performed $48 \mathrm{~h}$ after transfection. Data are presented as the mean $\pm \mathrm{SD}$ of $\mathrm{n}=3$. ${ }^{*} \mathrm{P}<0.05,{ }^{* * *} \mathrm{P}<0.01$, vs. miR-NC. GBM, glioblastoma multiforme; CCK- 8 , Cell Counting Kit-8; PI, propidium iodide; SD, standard deviation.

compared with the control cells (Fig. 2G). Furthermore, it was revealed that miR-767-5p mainly affected early apoptosis of cells, thus we primarily studied early apoptosis of cells in this experiment. Collectively, these findings indicated that miR-767-5p played a crucial role in regulating cell proliferation, colony formation, migration, and survival of glioma cell lines.

SUZ12 is a specific target gene of miR-767-5p and its expression is negatively correlated with miR-767-5p levels in GBM tissue. To elucidate the mechanisms by which miR-767-5p may inhibit GBM behavior, the bioinformatics analytical tool TargetScan was used to identify mRNAs containing 3'UTR sequences complementary to miR-767-5p. Of the potential targets identified, SUZ12 were selected for further analysis. SUZ12 is a component of the PRC2 complex, which controls gene expression through its histone methyltransferase activity and plays crucial roles in promoting cancer cell growth and invasion. To determine whether miR-767-5p does indeed interact with SUZ12 mRNA, we cloned the 3'UTR of SUZ12, either WT or mutated in the putative miR-767-5p binding site (Mut) into a luciferase reporter vector (Fig. 3A), which was transfected into U87 and U251 cells together with miR-767-5p or miR-NC. The results revealed that co-transfection with miR-767-5p significantly inhibited luciferase activity driven by SUZ12-WT, but not by SUZ12-Mut (Fig. 3B), indicating that miR-767-5p may regulate SUZ12 expression in GBM cells. Consistent with this, IHC staining revealed strong expression of SUZ12 and the proliferation marker Ki-67 in GBM tissues compared with NBTs (Fig. 3C). Furthermore, western blot analysis revealed that SUZ12 expression in the GBM cell lines was downregulated by overexpression of miR-767-5p (Fig. 3D) Notably, SUZ12 mRNA levels were much higher in GBM tissues than NBTs (Fig. 3E), which was in contrast with the pattern of miR-767-5p expression. In fact, Pearson's analysis revealed a significant negative correlation 
A

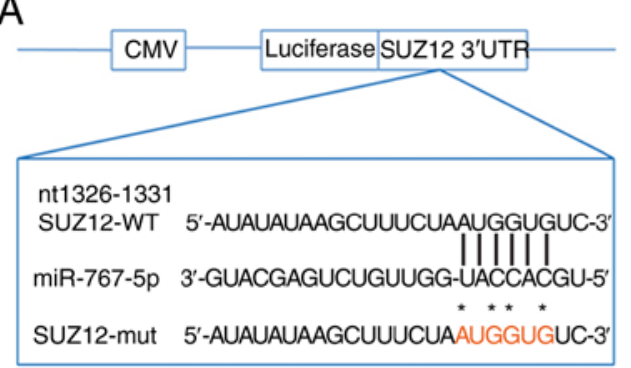

B

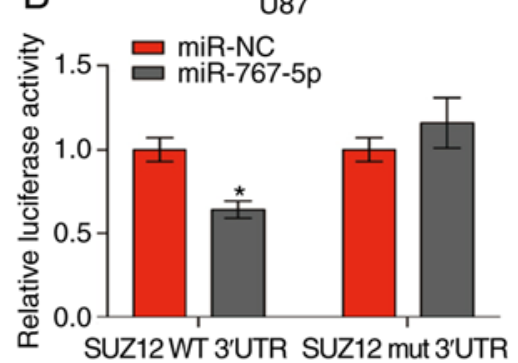

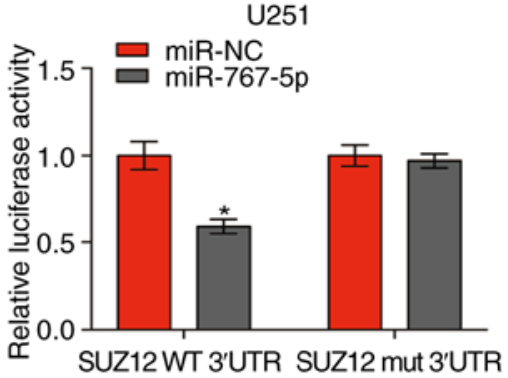

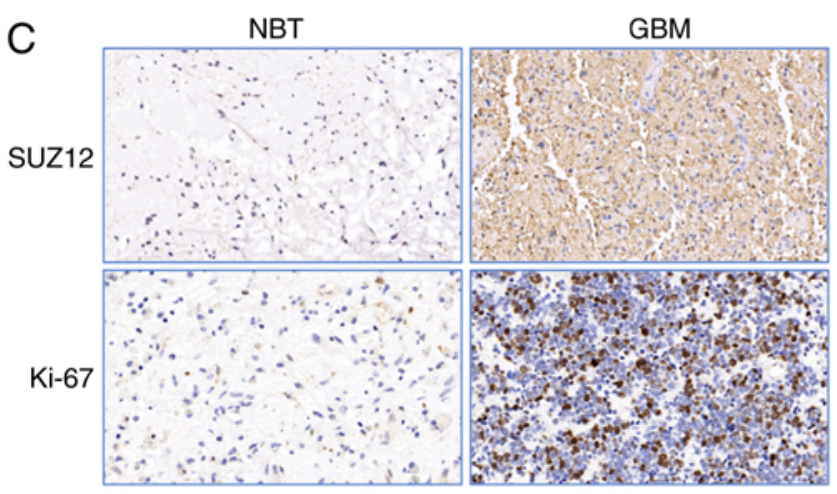

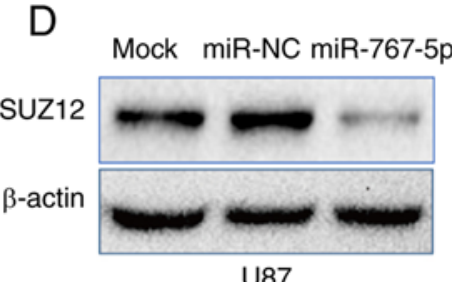

U87

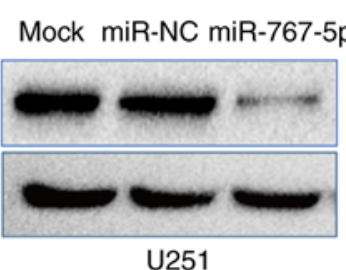

U251
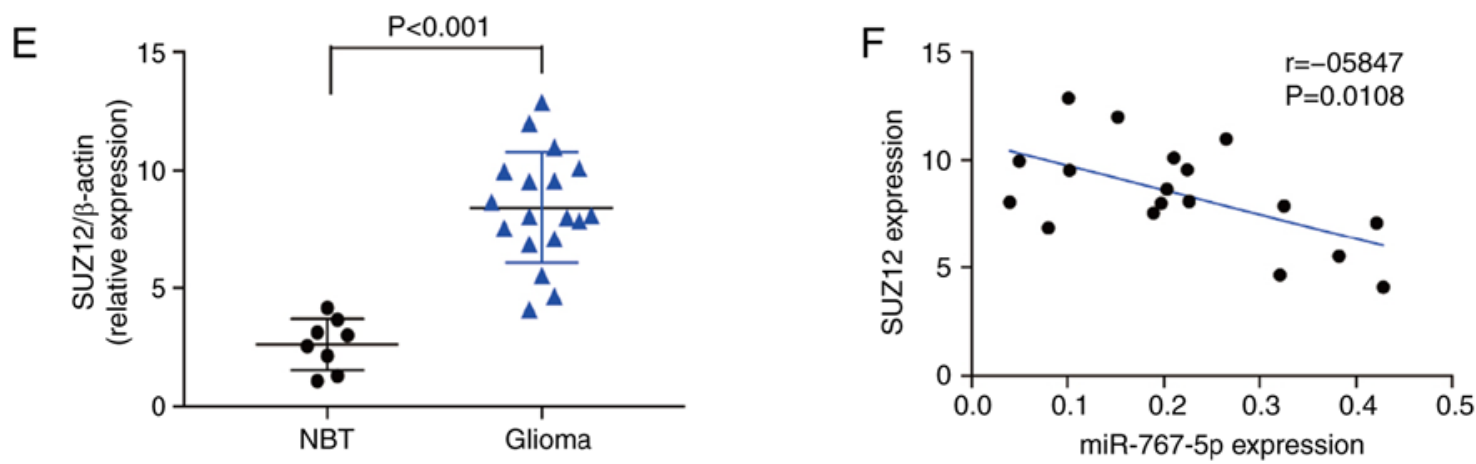

Figure 3. miR-767-5p regulates the expression of SUZ12 in GBM. (A) Predicted miR-767-5p binding site in the 3 'UTR of SUZ12 mRNA indicating the residues changed in the mutant construct. (B) Relative luciferase activity driven by the WT or Mut SUZ12 3'UTR in U87 and U251 cells co-transfected with miR-767-5p mimic or a control sequence (miR-NC). Firefly luciferase activity was normalized to Renilla luciferase. (C) Representative IHC staining of SUZ12 and Ki-67 in GBM and NBT. (D) Western blot analysis of SUZ12 protein levels in U87 and U251 cells expressing miR-767-5p or miR-NC. $\beta$-actin was probed as a loading control. (E) Relative expression of SUZ12 determined by western blot analysis of 18 GBM and 8 NBT specimens. SUZ12 levels were normalized to $\beta$-actin. (F) Pearson's correlation analysis of SUZ12 and miR-767-5p expression in 18 GBM tissues (Spearman correlation analysis, $\mathrm{r}=-0.5847$, $\mathrm{P}=0.0108$ ). Data are presented as the mean \pm SD of three independent experiments. ${ }^{*} \mathrm{P}<0.05$. SUZ12, suppressor of zeste-12; GBM, glioblastoma multiforme; 3 'UTR, 3 ' untranslated region; WT, wild-type; Mut, mutated; IHC, immunohistochemistry; NBT, normal brain tissue; SD, standard deviation.

between miR-767-5p and SUZ12 mRNA levels in GBM tissues (Fig. 3F; $r=-0.5847, P=0.0108$ ). Collectively, these data indicated that SUZ12 mRNA is a direct target of miR-767-5p in GBM.

Exogenous expression of SUZ12 overcomes the inhibitory effects of miR-767-5p on GBM cells. Previous research has revealed that SUZ12 plays a pivotal role in the proliferation and migration of many types of human cancers. To determine whether SUZ12 may mediate the effects of miR-767-5p on GBM cells, we assessed whether ectopic expression of SUZ12 could reverse the effects of miR-767-5p overexpression in U87 and U251 cells. RT-qPCR demonstrated that SUZ12 was increased compared to negative control groups (Fig. 4A). As revealed in Fig. 4, overexpression of SUZ12 partially or completely reversed the miR-767-5p-induced effects on cell proliferation (Fig. 4B), colony formation (Fig. 4C), migration
(Fig. 4D), invasion (Fig. 4E), cell cycle arrest (Fig. 4F), and apoptosis (Fig. 4G). Immunofluorescence staining of U87 and U251 cells confirmed that SUZ12 protein levels were markedly downregulated by transfection with miR-767-5p compared with miR-NC (Fig. 4H). Finally, whether miR-767-5p and SUZ12 modulation affected two major signaling pathways in GBM cells was examined. In fact, ERK1/2 and AKT pathway activation was suppressed by the miR-767-5p mimic, as demonstrated by a specific reduction of the phosphorylated (activated) forms of ERK1/2 and AKT (Fig. 4I). Notably, these miR-767-5p effects could be rescued by co-expression of SUZ12 (Fig. 4I). Thus, our data revealed that SUZ12 mediated the effects of miR-767-5p, at least in part, on glioma cell cancer-related behaviors.

Overexpression of miR-767-5p suppresses tumor growth in vivo. Having established the pivotal role played by 

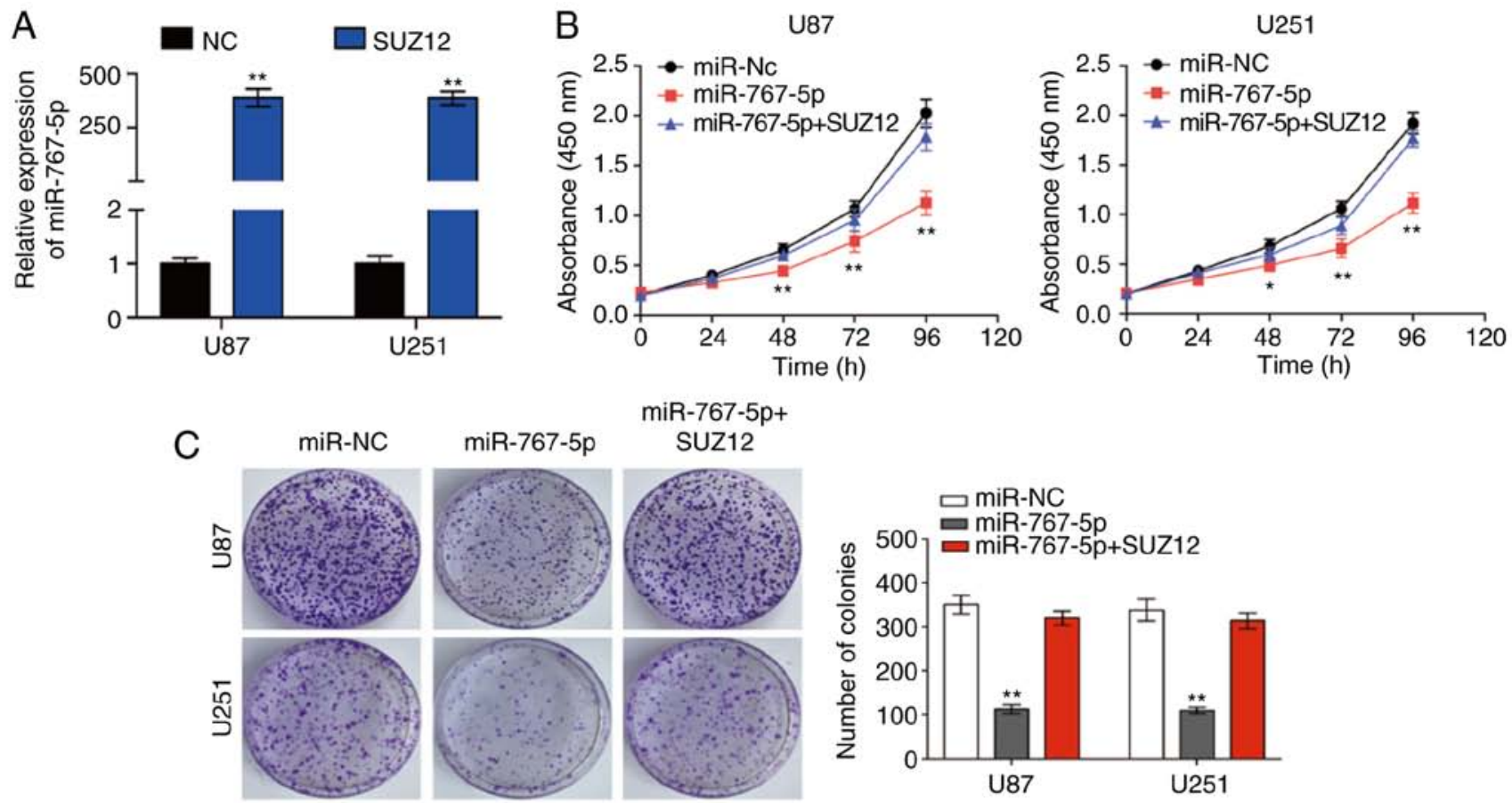

miR-767-5p+
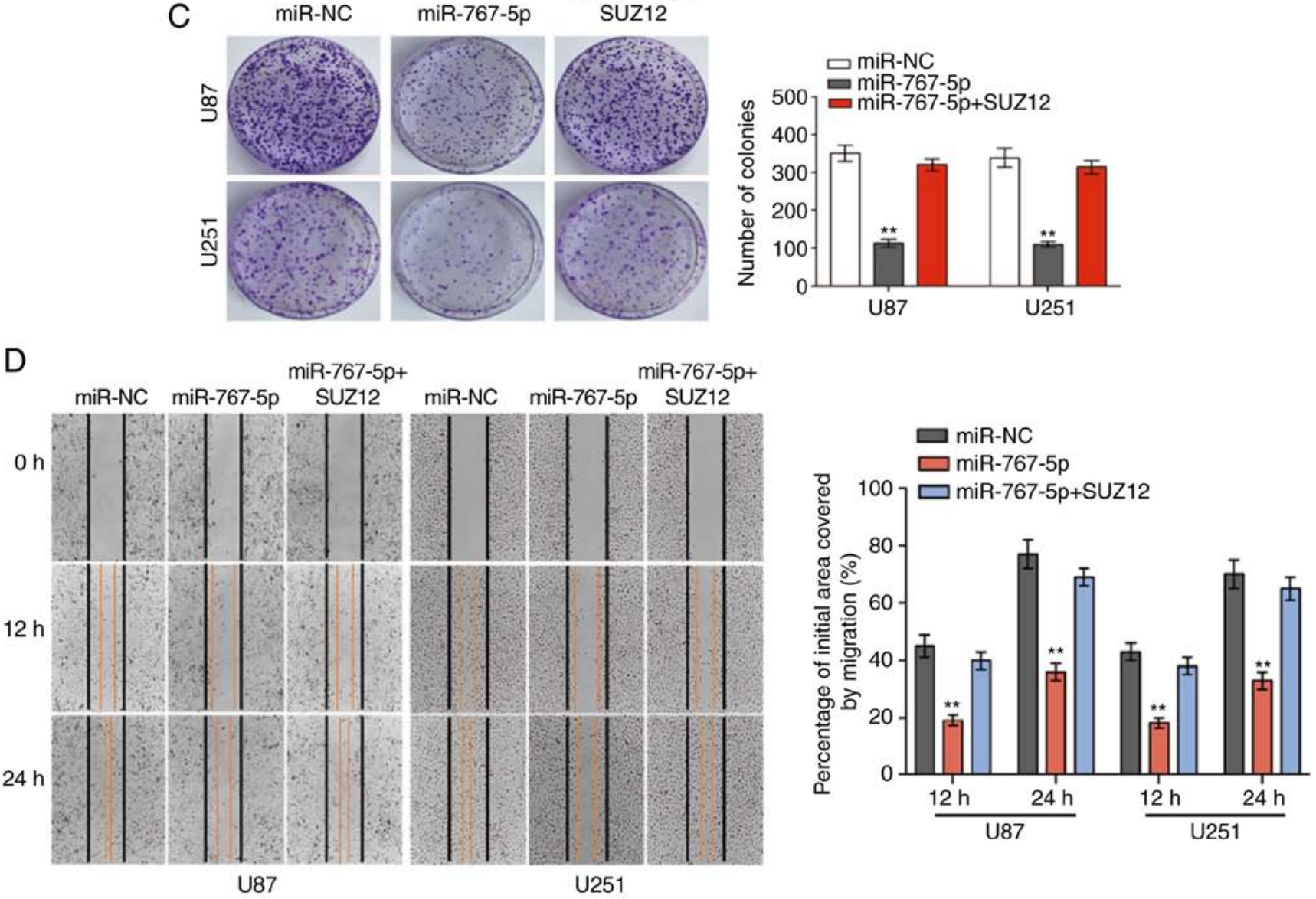

E
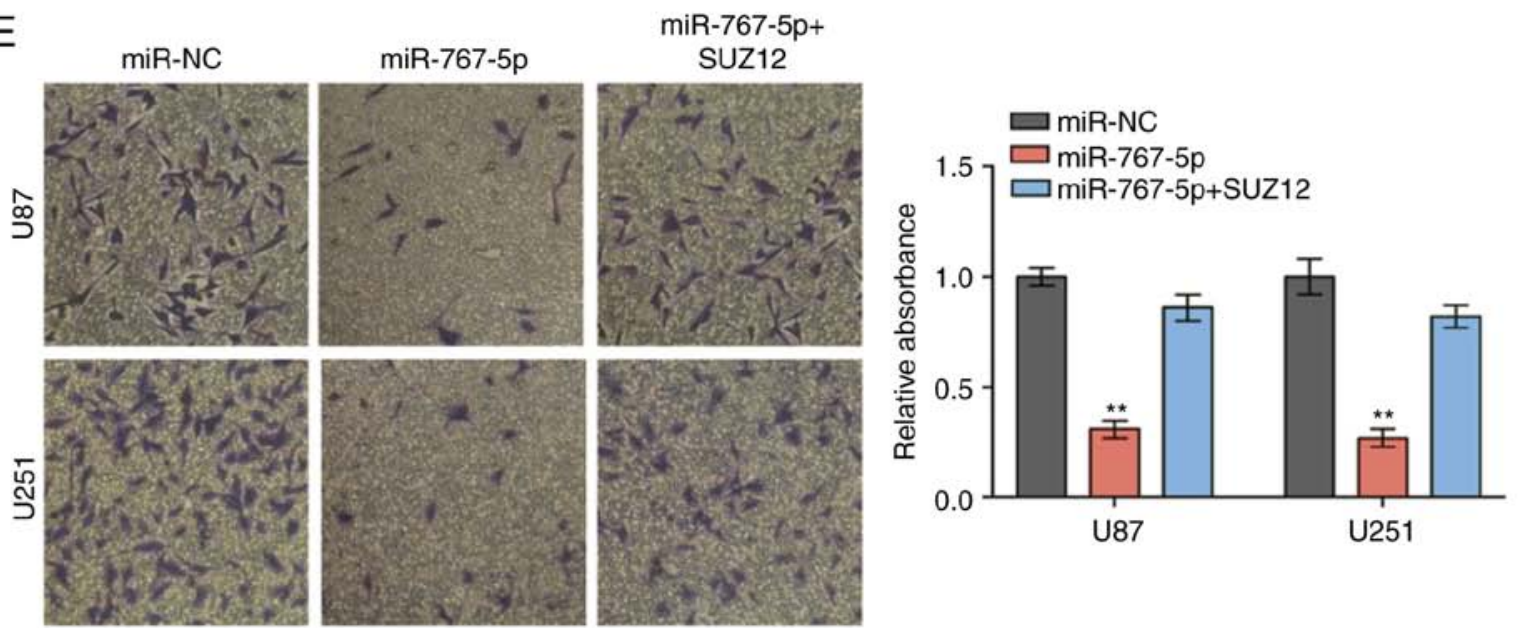

Figure 4. SUZ12 reverses the inhibitory effects of miR-767-5p on GBM cell lines. (A) The expression of SUZ12 in U87 and U251 cells was calculated by RT-qPCR after transfection. (B-I) For all assays, U87 and U251 cells were transfected with miR-767-5p mimic, negative control sequence (miR-NC), or miR-767-5p and a SUZ12 overexpression plasmid. (B) CCK-8 cell proliferation assay. (C and D) Representative images (left) and quantification (right) of (C) colony-forming assays, (D) wound healing assays, and (E) Transwell invasion assays. 

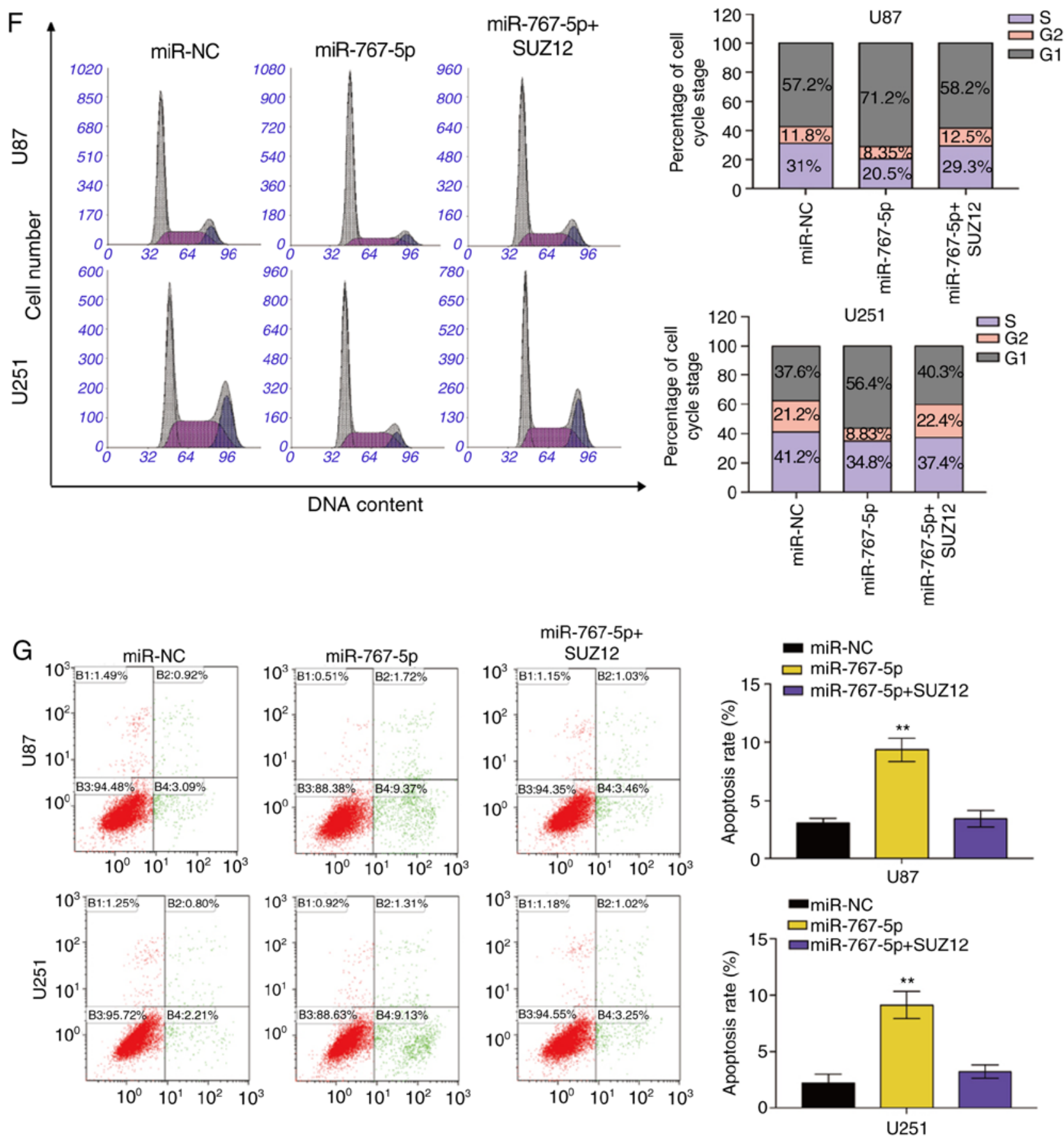

Figure 4. Continued. (F) Flow cytometric analysis of the cell cycle analyzed $48 \mathrm{~h}$ after transfection representative histograms (left) and quantification (right) of the percentage of cells in G1, G2, and S phases of the cell cycle. (G) Representative dot plots (left) and quantification (right) of an Annexin V-FITC/PI apoptosis assay. (H) Representative images of immunofluorescence staining of SUZ12 in U87 and U251 cells. Nuclei were stained with DAPI.

miR-767-5p in regulating GBM functions in vitro, its effects on tumor growth in vivo were next examined, using a mouse xenograft model. For this, U87 cells stably expressing miR-767-5p or miR-NC were injected subcutaneously into nude mice, and tumor growth was monitored over the next 30 days. As revealed in Fig. 5A-C, tumors derived from miR-767-5p-expressing U87 cells grew significantly slower and formed significantly smaller tumors than the miR-NC-expressing cells. miR-767-5p-overexpressing tumors excised after 30 days contained markedly reduced levels of SUZ12 and Ki-67 proteins compared with the miR-NC-expressing tumors, as determined by both IHC (Fig. 5D) and immunofluorescence
(Fig. 5E) staining. These results indicated that overexpression of miR-767-5p suppressed GBM growth in vivo, potentially via the effects on SUZ12.

\section{Discussion}

The miRNA class of small non-coding RNAs is increasingly recognized to play important roles in tumor activation or suppression via regulation of many genes involved in cancer progression and metastasis $(34,35)$. Deregulated miRNA expression has been revealed in many tumors, including the most common and malignant glioblastoma subtypes (36). 


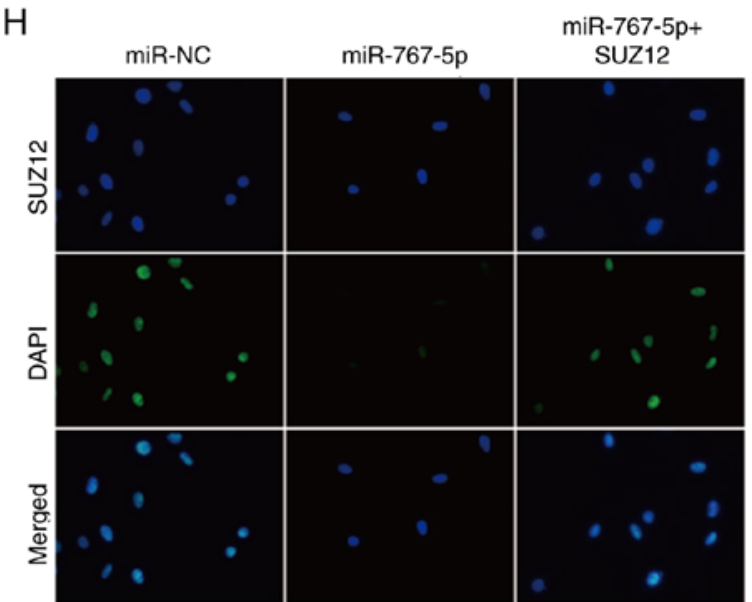

U87

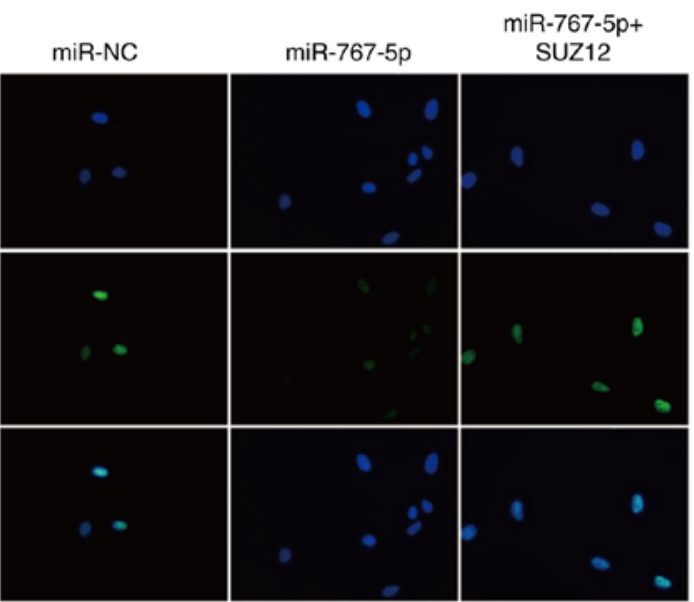

U251
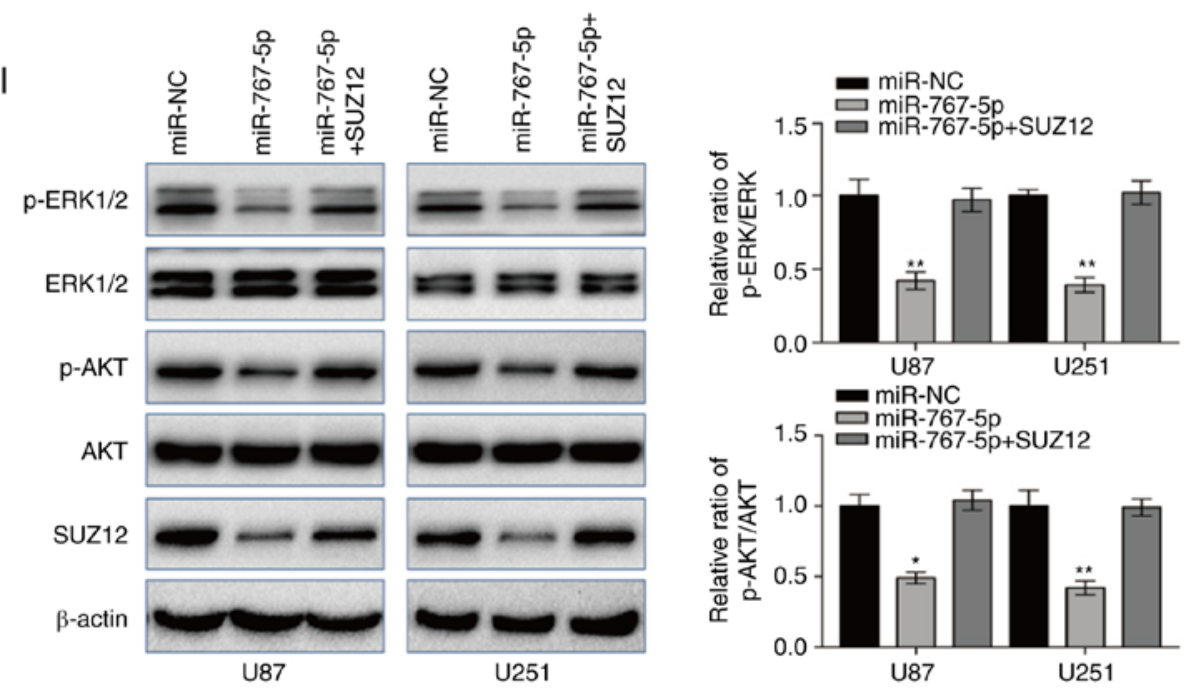

Figure 4. Continued. (H) Representative images of immunofluorescence staining of SUZ12 in U87 and U251 cells. Nuclei were stained with DAPI. (I) Western blot analysis of SUZ12, phosphorylated (p)-ERK1/2, total ERK1/2, p-AKT, and total AKT levels (left) and quantification of relative p-AKT and p-ERK levels (right). $\beta$-actin was probed as an internal control. Data are presented as the mean $\pm \mathrm{SD}$ of $\mathrm{n}=3$. ${ }^{*} \mathrm{P}<0.05,{ }^{* *} \mathrm{P}<0.01, \mathrm{miR}-767-5 \mathrm{p}$ vs. miR-767-5p+SUZ12. $\mathrm{SUZ12}$, suppressor of zeste-12; GBM, glioblastoma multiforme; CCK-8, Cell Counting Kit-8.

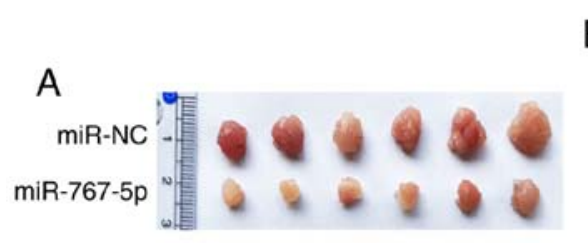

D

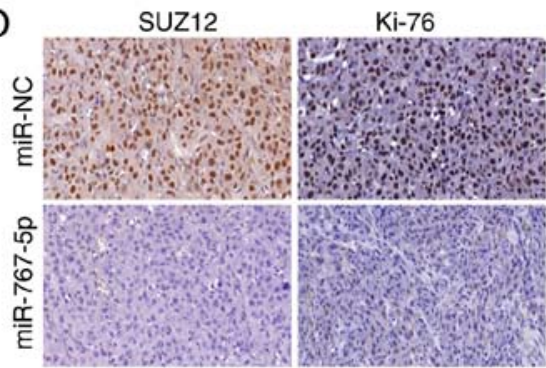

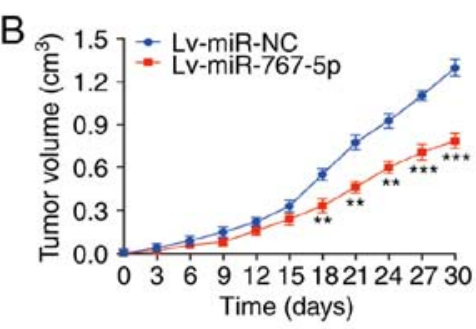
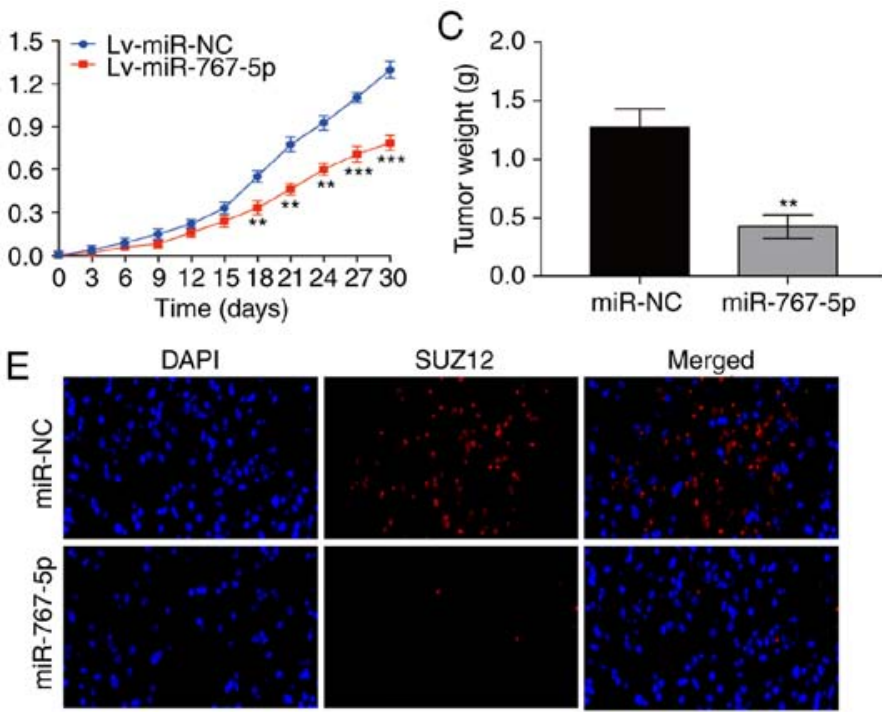

Figure 5. miR-767-5p overexpression suppresses tumor growth in a mouse xenograft model of GBM. (A) Representative images of tumors formed in nude mice 30 days after subcutaneous injection of U87 cells expressing miR-767-5p or a negative control sequence (miR-NC). (B) Tumor volumes. (C) Mean tumor weights at 30 days after inoculation. (D) Representative images of IHC staining of SUZ12 and Ki-67 proteins in tumor. (E) Representative images of immunofluorescence staining of SUZ12 in sections of tumors excised at 30 days. Nuclei were stained with DAPI. Data are presented as the mean \pm SD of three independent experiments. ${ }^{* *} \mathrm{P}<0.01,{ }^{* * * *} \mathrm{P}<0.001$. GBM, glioblastoma multiforme; SUZ12, suppressor of zeste-12; IHC, immunohistochemistry. 
Notably, the aberrant expression of a single miRNA can have profound implications for the expression of various transcripts that play an important role in human disease. Multiple miRNAs have been implicated in several crucial processes in glioma, such as cell proliferation, apoptosis, and invasion (37-39). In the present study, the biological role of miR-767-5p and its target gene SUZ12 were explored in glioma biology.

The present study revealed that miR-767-5p levels were significantly reduced in glioma compared with NBT based on data from the CGGA database and direct analysis of tissue samples. It was also revealed that miR-767-5p expression was significantly lower in glioma cell lines than in NHAs, and forced expression of miR-767-5p significantly inhibited cell growth, migration, and invasion, and induced cell cycle arrest and apoptosis. Notably, the inhibitory effect of miR-767-5p was partially or completely abolished by ectopic expression of its target gene SUZ12. Western blot analysis and luciferase reporter assays confirmed that miR-767-5p negatively regulates the expression of SUZ12 by binding to the SUZ12 3'UTR in glioma cells, leading to downregulation of SUZ12 protein. Our study thus describes the first experimental validation of a miR-767-5p target gene. The clinical relevance of our findings was also confirmed by demonstrating the ability of miR-767-5p overexpression to suppress the growth of human GBM tumors in nude mice. To the best of our knowledge, this is the first evidence that miR-767-5p is a tumor suppressive miRNA.

SUZ12 is a component of PRC2, a crucial regulator of multiple cellular functions. A recent study revealed that SUZ12 protein is overexpressed in a variety of cancers, including ovarian (40) and colorectal cancer (41), and mantle cell lymphoma (28). PRC2 is known to regulate the expression of various oncogenes. While the molecular mechanism of SUZ12 upregulation observed in glioma was previously unclear, there is growing evidence that miRNAs may be involved, consistent with our findings in the present study. For example, SUZ12 expression was regulated by $\mathrm{miR}-200 \mathrm{~b} / \mathrm{c}$, and overexpression of this miRNA inhibited cholangiocarcinoma tumorigenesis and metastasis (42). Our data in the present study are the first to reveal that miR-767-5p specifically targets SUZ12 in glioma. SUZ12 levels were correlated inversely with miR-767-5p in glioma tumor tissues, and forced SUZ12 overexpression overcame the inhibitory effects of miR-767-5p in GBM cells. Finally, downregulation of SUZ12 by miR-767-5p inhibited the phosphorylation of ERK1/2 and AKT, suggesting a potential molecular mechanism for its activity. Collectively, our data provide the first evidence that miR-767-5p suppresses glioma cell growth and metastasis by inhibiting SUZ12 translation.

We propose that miR-767-5p and SUZ12 could be useful novel prognostic markers as well as potential therapeutic targets for GBM. Collectively, these findings provide important new insights into the molecular mechanisms underlying glioma development and reveal potential new approaches to its treatment.

\section{Acknowledgements}

Not applicable.

\section{Funding}

This present study was supported by the Jiangsu Provincial Department of Health General Program [H201506 (EA15)], and the Program for Advanced Talents within Six Industries of Jiangsu Province [2015-WSN-023 (IB15)].

\section{Availability of data and materials}

The datasets used during the present study are available from the corresponding author upon reasonable request.

\section{Authors' contributions}

$\mathrm{XL}$ and JialZ proposed and designed this research. JialZ, SX and JX conducted the experiments. YL was responsible for the collection and analysis of the patients' data. JianZ and JieZ participated in the design of the study and assisted in drafting the manuscript. XL and JialZ wrote this manuscript. XL, JialZ, SX, JX, YL, JieZ and JianZ reviewed and edited the manuscript. All authors have read and approved the manuscript and agreed to be responsible for all aspects of the study to ensure proper investigation and resolution of the accuracy or integrity of any part of the work.

\section{Ethics approval and consent to participate}

The present study was approved by the Research Ethics Committee of Nanjing Medical University, and written informed consent was obtained from all patients. All animal experiments were approved by the Animal Management Rule of the Chinese Ministry of Health (Document 55, 2001) and were conducted in accordance with the approved guidelines and experimental protocols of Nanjing Medical University.

\section{Patient consent for publication}

Informed consent was obtained from all individual participants included in the study.

\section{Competing interests}

The authors declare that they have no conflict of interest.

\section{References}

1. Ohgaki $\mathrm{H}$ and Kleihues $\mathrm{P}$ : Genetic alterations and signaling pathways in the evolution of gliomas. Cancer Sci 100: 2235-2241, 2009.

2. Louis DN, Ohgaki H, Wiestler OD, Cavenee WK, Burger PC, Jouvet A, Scheithauer BW and Kleihues P: The 2007 WHO classification of tumours of the central nervous system. Acta Neuropathol 114: 97-109, 2007.

3. Ng SS, Cheung YT, An XM, Chen YC, Li M, Li GH, Cheung W, Sze J, Lai L, Peng Y, et al: Cell cycle-related kinase: A novel candidate oncogene in human glioblastoma. J Natl Cancer Inst 99: 936-948, 2007.

4. Stupp R, Mason WP, van den Bent MJ, Weller M, Fisher B, Taphoorn MJ, Belanger K, Brandes AA, Marosi C, Bogdahn U, et al: Radiotherapy plus concomitant and adjuvant temozolomide for glioblastoma. N Engl J Med 352: 987-996, 2005.

5. Lai EC: Micro RNAs are complementary to 3'UTR sequence motifs that mediate negative post-transcriptional regulation. Nat Genet 30: 363-364, 2002. 
6. Huntzinger E and Izaurralde E: Gene silencing by microRNAs: Contributions of translational repression and mRNA decay. Nat Rev Genet 12: 99-110, 2011.

7. Fu LL, Wen X, Bao JK and Liu B: MicroRNA-modulated autophagic signaling networks in cancer. Int J Biochem Cell Biol 44: 733-736, 2012.

8. van Jaarsveld MT, Helleman J, Berns EM and Wiemer EA: MicroRNAs in ovarian cancer biology and therapy resistance. Int J Biochem Cell Biol 42: 1282-1290, 2010.

9. Janga SC and Vallabhaneni S: MicroRNAs as post-transcriptional machines and their interplay with cellular networks. Adv Exp Med Biol 722: 59-74, 2011.

10. Paulin R, Courboulin A, Barrier M and Bonnet S: From oncoproteins/tumor suppressors to microRNAs, the newest therapeutic targets for pulmonary arterial hypertension. J Mol Med (Berl) 89: 1089-1101, 2011.

11. Chen CZ: MicroRNAs as oncogenes and tumor suppressors. $\mathrm{N}$ Engl J Med 353: 1768-1771, 2005.

12. Gabriely G, Yi M, Narayan RS, Niers JM, Wurdinger T, Imitola J, Ligon KL, Kesari S, Esau C, Stephens RM, et al: Human glioma growth is controlled by microRNA-10b. Cancer Res 71: 3563-3572, 2011.

13. Zhang CZ, Zhang JX, Zhang AL, Shi ZD, Han L, Jia ZF, Yang WD, Wang GX, Jiang T, You YP, et al: miR-221 and miR-222 target PUMA to induce cell survival in glioblastoma. Mol Cancer 9: 229, 2010.

14. Di Leva G, Garofalo M and Croce CM: MicroRNAs in cancer Annu Rev Pathol 9: 287-314, 2014.

15. Cho WC: OncomiRs: The discovery and progress of microRNAs in cancers. Mol Cancer 6: 60, 2007.

16. Esquela-Kerscher A and Slack FJ: Oncomirs-microRNAs with a role in cancer. Nat Rev Cancer 6: 259-269, 2006.

17. Volinia S, Calin GA, Liu CG, Ambs S, Cimmino A, Petrocca F, Visone R, Iorio M, Roldo C, Ferracin M, et al: A microRNA expression signature of human solid tumors defines cancer gene targets. Proc Natl Acad Sci USA 103: 2257-2261, 2006.

18. Chan JA, Krichevsky AM and Kosik KS: MicroRNA-21 is an antiapoptotic factor in human glioblastoma cells. Cancer Res 65 : 6029-6033, 2005.

19. Lu J, Getz G, Miska EA, Alvarez-Saavedra E, Lamb J, Peck D Sweet-Cordero A, Ebert BL, Mak RH, Ferrando AA, et al: MicroRNA expression profiles classify human cancers. Nature 435: 834-838, 2005.

20. Wang V and Wu W: MicroRNA-based therapeutics for cancer BioDrugs 23: 15-23, 2009.

21. Chase A and Cross NC: Aberrations of EZH2 in cancer. Clin Cancer Res 17: 2613-2618, 2011.

22. Bracken AP, Dietrich N, Pasini D, Hansen KH and Helin K: Genome-wide mapping of polycomb target genes unravels their roles in cell fate transitions. Genes Dev 20: 1123-1136, 2006.

23. Iliopoulos D, Lindahl-Allen M, Polytarchou C, Hirsch HA Tsichlis PN and Struhl K: Loss of miR-200 inhibition of Suz12 leads to polycomb-mediated repression required for the formation and maintenance of cancer stem cells. Mol Cell 39: 761-772, 2010.

24. Villa R, Pasini D, Gutierrez A, Morey L, Occhionorelli M, Viré E, Nomdedeu JF, Jenuwein T, Pelicci PG, Minucci S, et al: Role of the polycomb repressive complex 2 in acute promyelocytic leukemia. Cancer Cell 11: 513-525, 2007.

25. Herranz N, Pasini D, Díaz VM, Francí C, Gutierrez A, Dave N, Escrivà M, Hernandez-Muñoz I, Di Croce L, Helin K, et al: Polycomb complex 2 is required for E-cadherin repression by the Snaill transcription factor. Mol Cell Biol 28: 4772-4781, 2008.

26. Fan Y, Shen B, Tan M, Mu X, Qin Y, Zhang F and Liu Y: TGF- $\beta$-induced upregulation of malat1 promotes bladder cancer metastasis by associating with suz12. Clin Cancer Res 20 : $1531-1541,2014$
27. Cui Y, Chen J, He Z and Xiao Y: SUZ12 depletion suppresses the proliferation of gastric cancer cells. Cell Physiol Biochem 31: 778-784, 2013.

28. Martin-Perez D, Sanchez E, Maestre L, Suela J, Vargiu P, Di Lisio L, Martínez N, Alves J, Piris MA and Sánchez-Beato M: Deregulated expression of the polycomb-group protein SUZ12 target genes characterizes mantle cell lymphoma. Am J Pathol 177: 930-942, 2010.

29. Livak KJ and Schmittgen TD: Analysis of relative gene expression data using real-time quantitative PCR and the 2(-Delta Delta C(T)) method. Methods 25: 402-408, 2001.

30. Zhang J, Zhang J, Zhang J, Qiu W, Xu S, Yu Q, Liu C, Wang Y, Lu A, Zhang J and Lu X: MicroRNA-625 inhibits the proliferation and increases the chemosensitivity of glioma by directly targeting AKT2. Am J Cancer Res 7: 1835-1849, 2017.

31. Henriksen JR, Haug BH, Buechner J, Tømte E, Løkke C, Flaegstad T and Einvik C: Conditional expression of retrovirally delivered anti-MYCN shRNA as an in vitro model system to study neuronal differentiation in MYCN-amplified neuroblastoma. BMC Dev Biol 11: 1, 2011

32. Wang G, Mao W and Zheng S: MicroRNA-183 regulates Ezrin expression in lung cancer cells. FEBS Lett 582: 3663-3668, 2008.

33. Wang YY, Sun G, Luo H, Wang XF, Lan FM, Yue X, Fu LS, Pu PY, Kang CS, Liu N and You YP: miR-21 modulates hTERT through a STAT3-dependent manner on glioblastoma cell growth. CNS Neurosci Ther 18: 722-728, 2012.

34. Bartel DP: MicroRNAs: Target recognition and regulatory functions. Cell 136: 215-233, 2009.

35. Bartel DP: MicroRNAs: Genomics, biogenesis, mechanism, and function. Cell 116: 281-297, 2004.

36. Møller HG, Rasmussen AP, Andersen HH, Johnsen KB, Henriksen M and Duroux M: A systematic review of microRNA in glioblastoma multiforme: Micro-modulators in the mesenchymal mode of migration and invasion. Mol Neurobiol 47: 131-144, 2013.

37. Huang Q, Gumireddy K, Schrier M, le Sage C, Nagel R, Nair S, Egan DA, Li A, Huang G, Klein-Szanto AJ, et al: The microRNAs miR-373 and miR-520c promote tumour invasion and metastasis. Nat Cell Biol 10: 202-210, 2008.

38. Bou Kheir T, Futoma-Kazmierczak E, Jacobsen A, Krogh A, Bardram L, Hother C, Grønbæk K, Federspiel B, Lund AH and Friis-Hansen L: miR-449 inhibits cell proliferation and is down-regulated in gastric cancer. Mol Cancer 10: 29, 2011.

39. Mott JL, Kobayashi S, Bronk SF and Gores GJ: mir-29 regulates Mcl-1 protein expression and apoptosis. Oncogene 26: 6133-6140, 2007.

40. Li H, Cai Q, Wu H, Vathipadiekal V, Dobbin ZC, Li T, Hua X, Landen CN, Birrer MJ, Sánchez-Beato M and Zhang R: SUZ12 promotes human epithelial ovarian cancer by suppressing apoptosis via silencing HRK. Mol Cancer Res 10: 1462-1472, 2012.

41. Liu YL, Gao X, Jiang Y, Zhang G, Sun ZC, Cui BB and Yang YM: Expression and clinicopathological significance of EED, SUZ12 and EZH2 mRNA in colorectal cancer. J Cancer Res Clin Oncol 141: 661-669, 2015.

42. Peng F, Jiang J, Yu Y, Tian R, Guo X, Li X, Shen M, Xu M, Zhu F, Shi C, et al: Direct targeting of SUZ12/ROCK2 by miR-200b/c inhibits cholangiocarcinoma tumourigenesis and metastasis. $\mathrm{Br}$ J Cancer 109: 3092-3104, 2013.

This work is licensed under a Creative Commons Attribution-NonCommercial-NoDerivatives 4.0 International (CC BY-NC-ND 4.0) License. 